\title{
Characterisation of anaemia amongst school going adolescent girls in rural Haryana, India
}

\author{
Aakriti Gupta ${ }^{1, *}$, Harshpal Singh Sachdev², Umesh Kapil ${ }^{3}$, Shyam Prakash 4 , \\ Ravindra Mohan Pandey ${ }^{5}$, Hem Chandra Sati ${ }^{5}$, Lokesh Kumar Sharma ${ }^{6}$ and \\ Priti Rishi Lal ${ }^{1}$ \\ 'Department of Food and Nutrition, Lady Irwin College, University of Delhi, New Delhi 1 10001, India: ${ }^{2}$ Department of \\ Pediatrics and Clinical Epidemiology, Sitaram Bhartia Institute of Science and Research, New Delhi, India: \\ ${ }^{3}$ Department of Human Nutrition, All India Institute of Medical Sciences, New Delhi, India: ${ }^{4}$ Department of Laboratory \\ Medicine, All India Institute of Medical Sciences, New Delhi, India: ${ }^{5}$ Department of Biostatistics, All India Institute of \\ Medical Sciences, New Delhi, India: ${ }^{6}$ Department of Biochemistry, Dr. Ram Manohar Lohia Hospital, New Delhi, India
}

Submitted 15 September 2021: Final revision received 11 January 2022: Accepted 19 January 2022: First published online 24 January 2022

\begin{abstract}
Objective: High burden of anaemia exists amongst rural adolescent girls in India. The objective of this study was to characterise anaemia in school going adolescent girls in rural Haryana, India.

Design: Linear and multiple logistic regression analysis of data collected prior to an intervention trial was conducted. Participants were classified into anaemic (haemoglobin $<12 \mathrm{~g} / \mathrm{dl}$ ) and non-anaemic group and were further classified into deficiencies of $\mathrm{Fe}$, folate or vitamin $\mathrm{B}_{12}$, mixed, anaemia of other causes and inflammation.

Setting: Three schools in Ballabgarh block of Faridabad District, Haryana, India. Participants: One hundered and ninety-eight non-anaemic and 202 anaemic adolescent girls (12-19 years).

Results: Anaemic girls had 29.6\% Fe deficiency, $28.1 \%$ folate or vitamin $\mathrm{B}_{12}$ deficiency, $15.8 \%$ mixed deficiency and $9.7 \%$ acute inflammation. Anaemia of other causes was found in $16.8 \%$ of the anaemic participants. Girls with Fe and isolated folate deficiency had 2.5 times and four times higher odds of developing anaemia, respectively, as compared with non-anaemic girls. Fe deficiency with no anaemia was found amongst $11 \%$ non-anaemic girls. Non-anaemic girls had a high prevalence of combined deficiency of folate or vitamin $\mathrm{B}_{12}(29.5 \%)$ and acute inflammation (14.4\%).

Conclusions: The current strategy of Fe and folic acid supplementation alone will not suffice for achieving the desired reduction in the prevalence of anaemia as unknown causes and anaemia of inflammation contribute to a substantial proportion of anaemia. Integrating other nutrition-specific components like improving water, sanitation and hygiene practices with the ongoing micronutrient supplementation program will comprehensively tackle anaemia. Unknown causes of anaemia warrant further research.
\end{abstract}

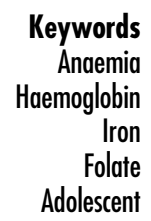

Anaemia in adolescent girls is a major public health problem in India with $40 \%$ being afflicted ${ }^{(1)}$. Adolescent girls are vulnerable to anaemia due to regular loss of $\mathrm{Fe}$ through menstrual blood in addition to the overall accelerated increase in requirements for Fe due to rapid pubertal growth. Functional consequences of anaemia on growth and development occur even at mild levels or prior to onset of clinical stage of anaemia, making it the third leading cause of disability in the world ${ }^{(2)}$.

Some recent evidence challenges the earlier notion that Fe deficiency is the predominant contributor to anaemia globally ${ }^{(3,4)}$. Estimates suggest that less than half the cases of anaemia are due to Fe deficiency, and the other causes are unknown ${ }^{(3-5)}$. Anaemia due to inflammation has been 
reported to further lower the proportion of anaemia associated with Fe deficiency (20\% for pre-school children; $25 \%$ for non-pregnant women of reproductive age ${ }^{(4)}$. Most strategies in India focus on increasing $\mathrm{Fe}$ intake, despite the fact that anaemia is multifactorial in aetiology and its prevalence varies among population groups and in different areas and local conditions ${ }^{(6)}$. The National Nutritional Anemia Control Program (Anemia Mukt Bharat) provides weekly Fe and folic acid (IFA) supplementation (60 mg elemental Fe and $500 \mathrm{mcg}$ of folic acid) and biannual de-worming to all in school children, through teachers and to out-of-school children, through quarterly Adolescent Health Day component of Rashtriya Kishor Swasthya Karyakram programme at Anganwadi centres ${ }^{(7)}$. However, a slow decline in the prevalence of anaemia has been observed amongst adolescent girls in India over the past decades as represented by National surveys ${ }^{(8)}$. With the current strategy and knowledge, we may not be able to achieve the national target of $3 \%$ percentage points per annum reduction in the prevalence of anaemia among adolescent girls and women in the age group of $15-49$ years.

Therefore, the present study was conducted to characterise anaemia, especially amongst rural adolescent girls as more than half of them reside in rural areas of the country $^{(9)}$.

\section{Methods}

\section{Study design, population and sampling techniques}

The present study was nested within a community-based cluster-randomised controlled trial conducted to assess the impact of daily supplementation of IFA alone or in combination with vitamin $\mathrm{B}_{12}$ amongst adolescent girls in the age group of 12-19 years living in the rural Ballabgarh block of Faridabad District, Haryana, India. We have analysed and presented the cross-sectional data at baseline of 400 girls within the framework of the randomised control trial.

Faridabad is predominantly (75.9\%) $\operatorname{urban}^{(10)}$ with $54.1 \%$ of the adolescents being anaemic (haemoglobin $<12 \mathrm{~g} / \mathrm{dl}$ ) as per NFHS- ${ }^{(11)}$. We selected Ballabgarh block of Faridabad district as $98 \%$ of its total population reside in rural areas ${ }^{(10)}$. According to the Annual Status of Education Report (2020), the overall school enrollment for rural adolescent girls has been above $90 \%$ in India and around $93 \%$ in the study area ${ }^{(12)}$. We compiled a list of all middle and senior secondary government schools in Ballabgarh block from which three schools in Dayalpur, Fatehpur Billoch and Chhainsa were selected for recruitment of study participants. All 1051 adolescent girls aged 12-19 years studying in 6-12th standard and who gave the informed consent were screened for haemoglobin. All non-anaemic participants with haemoglobin of $>12 \mathrm{~g} / \mathrm{dl}$
Table 1 Baseline measurements of socio-demographic profile of the enrolled and not enrolled participants

\begin{tabular}{|c|c|c|c|c|c|}
\hline \multirow{2}{*}{$\frac{\text { Baseline characteristics }}{\text { Age (years) }}$} & \multicolumn{2}{|c|}{$\begin{array}{c}\text { Enrolled } \\
\text { (n 400) }\end{array}$} & \multicolumn{2}{|c|}{$\begin{array}{c}\text { Not } \\
\text { enrolled* } \\
(n 651)\end{array}$} & \multirow{2}{*}{$\frac{P \text { value }}{0.06}$} \\
\hline & 14.5 & 1.8 & $14 \cdot 3$ & 1.7 & \\
\hline \multicolumn{6}{|c|}{ Per capita income (in Rs.) $\dagger$} \\
\hline$p_{50}$ & \multirow{2}{*}{\multicolumn{2}{|c|}{$\begin{array}{c}1250 \\
833-2000\end{array}$}} & \multirow{2}{*}{\multicolumn{2}{|c|}{$\begin{array}{c}1270 \\
800-2000\end{array}$}} & 0.37 \\
\hline $\mathrm{p}_{25}-\mathrm{p}_{75}$ & & & & & \\
\hline Height $(\mathrm{cm})$ & $150 \cdot 6$ & $7 \cdot 9$ & 148.9 & $8 \cdot 4$ & 0.001 \\
\hline Weight (kg) & $40 \cdot 4$ & 8.5 & 39.4 & 8.0 & 0.06 \\
\hline BMI $\left(\mathrm{kg} / \mathrm{m}^{2}\right)$ & $13 \cdot 3$ & $2 \cdot 5$ & $13 \cdot 1$ & $2 \cdot 3$ & 0.27 \\
\hline
\end{tabular}

*Not enrolled category includes those adolescent girls who were not selected from the community-based cluster-randomised controlled trial under which the present study was nested.

†Per capita income is expressed as the household's monthly income divided by the number of family members, and values are expressed as $p_{50}\left(p_{25}-p_{75}\right)$.

( $n$ 198) were included in the study. Using random number table, 202 participants with mild anaemia (haemoglobin level of $10-11.9 \mathrm{~g} / \mathrm{dl}: 41.7 \%$ ) and moderate anaemia (haemoglobin level of 7-9.9 g/dl: $51.9 \%$ ) were selected randomly. All fourteen participants (6.4\%) with severe anaemia (haemoglobin: $<7 \mathrm{~g} / \mathrm{dl}$ ) were excluded from the study and were referred to the nearest primary health centre for treatment. The socio-demographic profile of enrolled and not enrolled participants in the present study from the original community-based cluster-randomised controlled trial has been presented in Table 1. A flow chart of participant selection is available in Fig. 1.

\section{Biochemical assessment}

Haemoglobin estimation was undertaken using cyanmethhaemoglobin method ${ }^{(13)}$. Twenty microlitre of capillary blood was spotted on pre-labelled Whatman Filter paper no. 1. The filter paper was then allowed to dry and packed in zip pouch and transported to the central laboratory of All India Institute of Medical Sciences, New Delhi, India, for analysis. We used an indirect cyanmethhaemoglobin method using filter paper, as it was not feasible to transport whole venous blood within an hour under suitable conditions to the central laboratory.

Venous blood $(5 \mathrm{ml})$ was drawn simultaneously in plain vacutainers (Beckton Dickinson, Franklin Lakes, NJ, USA) for the biochemical investigations of serum ferritin, soluble transferrin receptor (sTfR), hepcidin, folic acid and vitamin $\mathrm{B}_{12}$ utilising standard operating procedures. Blood samples were centrifuged within $2 \mathrm{~h}$ of collection. The serum samples were transported to the central laboratory for biochemical estimations and thereafter kept at $-80{ }^{\circ} \mathrm{C}$. Internal quality control was maintained using standards/ controls with every batch of samples.

Serum ferritin was estimated by two-site sandwich immunoassay using direct chemiluminometric technique (Immulite-1000, Siemens, Berlin, Germany) ${ }^{(14)}$. Serum sTfR, hepcidin and folic acid levels were estimated by sandwich ELISA method ${ }^{(15)}$. Vitamin $\mathrm{B}_{12}$ estimation was done by 


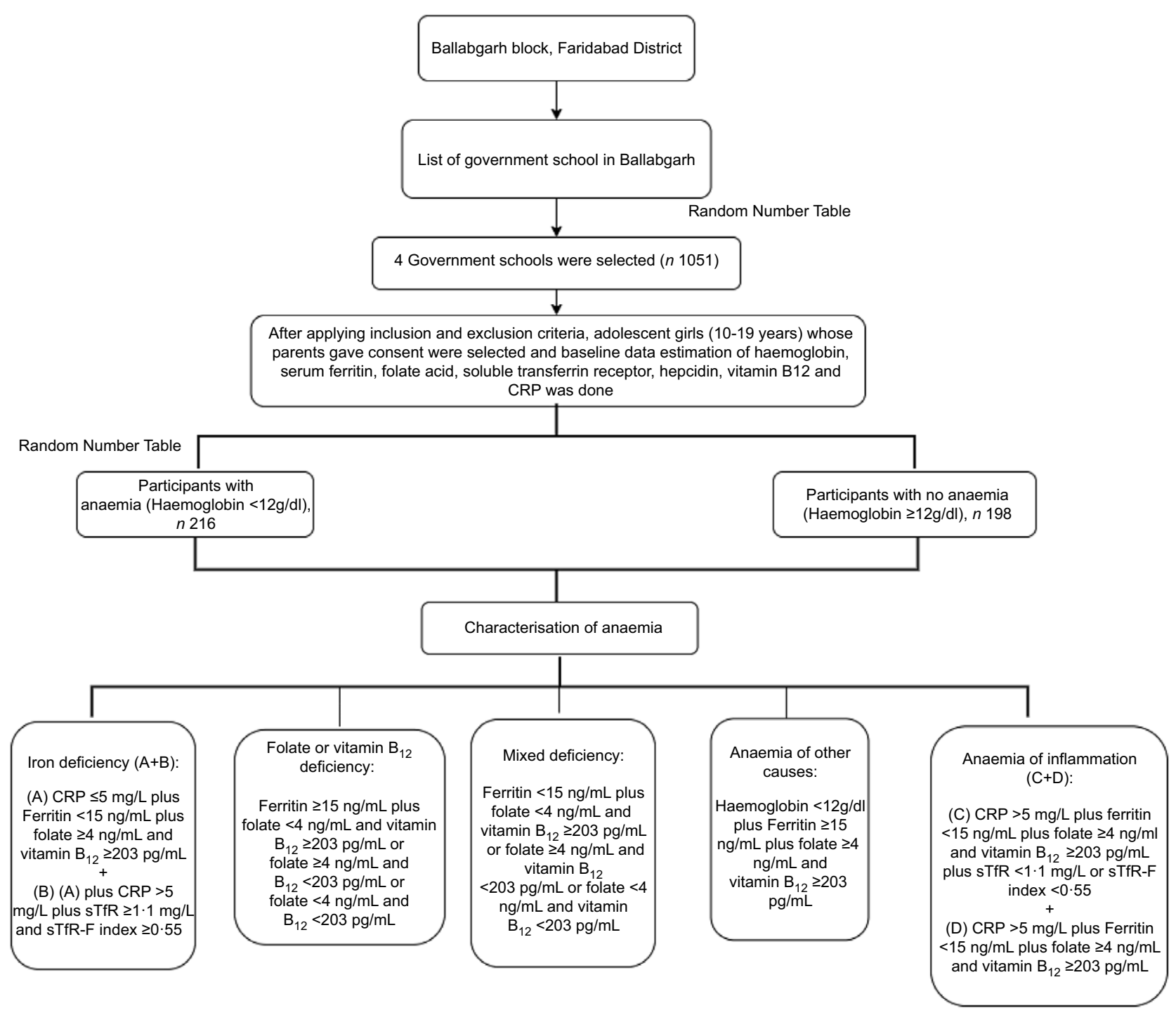

Fig. 1 Summary of the recruitment process

competitive immunoassay using direct chemiluminescent technique (Immulite-1000, Siemens, Berlin, Germany) ${ }^{(14)}$. High-sensitivity C-reactive protein (CRP) level was estimated by solid phase ELISA technique ${ }^{(15)}$.

\section{Outcome: anaemia}

The WHO cut-off (2011) of $<12 \mathrm{~g} / \mathrm{dl}$ for haemoglobin was utilised to define anaemia ${ }^{(16)}$. Participants were further classified as: mild (10-11.9 g/dl), moderate $(7-9.9 \mathrm{~g} / \mathrm{dl})$ and severe $(<7 \mathrm{~g} / \mathrm{dl})^{(16)}$.

\section{Exposures}

Biochemical levels of Fe, sTfR, hepcidin, folic acid, vitamin $\mathrm{B}_{12}$ and $\mathrm{CRP}$.

For the determination of Fe status, two biomarkers were used: ferritin and sTfR. Serum ferritin concentration of $<15 \mathrm{ng} / \mathrm{ml}$ was utilised to reflect the storage Fe compartment. Serum ferritin concentration of $<70 \mathrm{ng} / \mathrm{ml}$ was used as the cut-off for individuals with infection or inflammation $(\mathrm{CRP}>5 \mathrm{mg} / \mathrm{l})^{(17)}$. sTfR concentrations of $>1.1 \mathrm{mg} /$ l (ELISA kit-based cut-offs) were used to define functional $\mathrm{Fe}$ compartment and status of erythropoiesis (Kinesis DX, Cat No: K12-0282). Hepcidin concentration, a marker for assessing Fe homoeostasis, was defined using the ELISA kit-based cut-offs. The assay range of the kit was 50-800 ng/ml (Kinesis DX, Cat No: K12-1020). Elevated levels were defined as hepcidin $>400 \mathrm{ng} / \mathrm{ml}$ and low levels as $<100 \mathrm{ng} / \mathrm{ml}$. Vitamin $B_{12}$ deficiency was defined as serum vitamin $B_{12}$ level $<203 \mathrm{pg} / \mathrm{ml}$ and folate deficiency as a serum folate level $<4 \mathrm{ng} / \mathrm{ml}^{(18)}$. Acute inflammation was defined as CRP $>5 \mathrm{mg} / \mathrm{l}^{(19)}$.

\section{Characterisation of anaemia}

Participants were classified into the following aetiological categories $^{(5)}$ : (i) Fe deficiency was characterised as (A) ferritin deficiency plus sufficient folate and vitamin $B_{12}$ 
levels amongst participants with $\mathrm{CRP} \leq 5 \mathrm{mg} / \mathrm{l}$; and (B) A plus elevated sTfR and sTfR-ferritin index in participants with CRP $>5 \mathrm{mg} / \mathrm{l}$; (ii) folate or vitamin $\mathrm{B}_{12}$ deficiency was characterised as sufficient ferritin along with deficiency of either folate or vitamin $\mathrm{B}_{12}$ or both, irrespective of CRP concentrations; (iii) dimorphic anaemia/mixed deficiency was characterised as ferritin deficiency along with deficiency of either folate or vitamin $\mathrm{B}_{12}$ or both, irrespective of CRP concentrations; (iv) anaemia of other causes was characterised by low haemoglobin $(<12 \mathrm{~g} / \mathrm{dl})$ with sufficient ferritin, folate and vitamin $\mathrm{B}_{12}$ level amongst participants with CRP $\leq 5 \mathrm{mg} / \mathrm{l}$ and (v) anaemia of inflammation was characterised amongst participants with CRP $>5 \mathrm{mg} / \mathrm{l}$ as: (A) participants with ferritin deficiency along with sufficient folate, vitamin $\mathrm{B}_{12}$ and elevated sTfR or elevated sTfR-ferritin index and (B) sufficient ferritin, folate and vitamin $\mathrm{B}_{12}$ level.

\section{Potential confounders}

Age, type of diet, wealth index, water source, consumption of deworming tablets (past 1 year), IFA tablets (past $30 \mathrm{~d}$ ) and status of menstruation.

We used a pre-tested semi-structured questionnaire to elicit information on identification data, socio-demographic profile, type of house (Kutcha houses with mud walls and thatched/tiled roofs, semi-pucca houses with brick walls and tiled/asbestos/tin roofs and pucca houses with brick walls and reinforced cement concrete roofs), water source, toilet facility, diet and consumption of deworming tablets (past 1 year) and IFA tablets (past $30 \mathrm{~d}$ ).

\section{Wealth index}

We used a principal component analysis to construct a wealth assets index from the information collected on household ownership of consumer durables, the characteristics of the household's dwelling and household landownership ${ }^{(20)}$.

\section{Anthropometry}

Standing height was recorded barefoot, using a standard stadiometer (SECA 213) to the nearest $1 \mathrm{~mm}$. Participants were weighed using a weighing scale (SECA 813) to the nearest $0 \cdot 1 \mathrm{~kg}$, wearing minimal clothing and without shoes. BMI was calculated as weight $(\mathrm{kg}) /$ height $^{2}\left(\mathrm{~m}^{2}\right)$. The WHO BMI $Z$-scores were used to classify adolescent girls as severe thinness, thinness, normal and overweight $^{(21)}$. WHO height-for-age $Z$-scores classified children into normal, stunted and severely stunted categories ${ }^{(21)}$.

\section{Etbics statement}

After describing the objectives and risks of the study, an informed consent was obtained from the parents/ guardians of all the children. A written assent was obtained for children between 13 and 18 years. An additional oral assent was obtained from the children who were less than
13 years old in the presence of the parent/guardian representative. The consent was written for those parents/caretakers who are literate and oral (with a witness) along with thumb impression for those who were illiterate.

\section{Statistical analysis}

Stata/sE 13.0 version 13.0, StataCorp. software was used for statistical analysis of data. Quantitative data were expressed in mean \& SD for normally distributed variables, median $\left(25^{\text {th }}\right.$ percentile, $75^{\text {th }}$ percentile) for non-normally distributed continuous variables and frequency (percentage, \%) for categorical variables. We log-transformed serum ferritin to achieve normality and reported geometric mean and interquartile ranges. Two-sided $P$-value of $<0.05$ was regarded as statistically significant. We assessed association of different biochemical, socio-economic and demographic parameters with anaemia using Student's $t$-test, Chi-square test or Fischer exact test. Linear regression was performed to assess the association of factors with haemoglobin level as the outcome variable. Multiple logistic regression was used to examine the factors associated with anaemia. We adjusted for age (in years), CRP (in $\mathrm{mg} / \mathrm{l}$ ), caste (scheduled caste and tribes (SC/ST)/Other Backward Classes (OBC) $v$. Others), source of drinking water (Handpump $v$. Others), reported consumption of IFA in past month (yes $v$. no) and menstruation status (no $v$. yes) in our analysis.

\section{Results}

The general characteristics of the enrolled participants by anaemia status are presented in Table 1 . Approximately $2 / 3^{\text {rd }}$ of the participants were thin with $33.5 \%$ being severely thin (BMI $<-3$ SD). Stunting as defined by height for age $<-2$ SD was found in $18 \cdot 2 \%$ of the participants ${ }^{(21)}$.

\section{Comparison of participants with and without anaemia}

Adolescents with anaemia were significantly different from those without anaemia in characteristics, namely, greater age $(0.4$ years, $P=0.022), \mathrm{SC} / \mathrm{ST}(57.9 \%$ anaemic $v$. $43.3 \%$ non-anaemic; $P=0.003)$, nuclear families $(54.3 \%$ anaemic $v .45 .7 \%$ non-anaemic; $P=0.029)$, protected drinking water supply (piped water) $(45.4 \%$ anaemic $v$. $54.5 \%$ non-anaemic; $P=0.001$ ), reported consumption of IFA tablets in the past month $(48.2 \%$ anaemic $v$. $51.8 \%$ non-anaemic; $P=0.020)$ and menstruation $(56.2 \%$ anaemic $v .43 .8 \%$ non-anaemic; $P<0.000)$. The two groups were comparable for the other evaluated characteristics including height, weight, BMI, religion, per capita income, wealth index, type of house, type of toilet facility, type of diet and reported consumption of deworming tablets in the past month (Table 2). 
Characterisation of anaemia among rural girls

Table 2 Characteristics of adolescent girls aged 12-19 years enrolled in the study, stratified by anaemia status

\begin{tabular}{|c|c|c|c|c|c|}
\hline \multirow[b]{2}{*}{ Parameters } & \multicolumn{2}{|c|}{$\begin{array}{l}\text { Non-anaemia group } \\
\qquad(n 198)\end{array}$} & \multicolumn{2}{|c|}{$\begin{array}{l}\text { Anaemia group } \\
(n \text { 202) }\end{array}$} & \multirow[b]{2}{*}{$P$ value } \\
\hline & $n$ & $\%$ & $n$ & $\%$ & \\
\hline \multicolumn{6}{|l|}{ Age } \\
\hline Mean & $14 \cdot 3$ & & $14 \cdot 7$ & & 0.022 \\
\hline SD & $1.8^{*}$ & & $1.9^{*}$ & & \\
\hline \multicolumn{6}{|l|}{ Age category } \\
\hline $12-15$ years & 149 & $53 \cdot 4$ & 130 & $46 \cdot 6$ & 0.018 \\
\hline $16-19$ years & 49 & $40 \cdot 5$ & 72 & 59.5 & \\
\hline \multicolumn{6}{|l|}{ Height (cm) } \\
\hline Mean & $150 \cdot 3$ & & $151 \cdot 1$ & & 0.29 \\
\hline SD & $8 \cdot 5^{\star}$ & & $7 \cdot 3^{*}$ & & \\
\hline \multicolumn{6}{|l|}{ Weight (kg) } \\
\hline Mean & $40 \cdot 1$ & & $40 \cdot 7$ & & 0.53 \\
\hline SD & $9 \cdot 1$ & & $7 \cdot 7$ & & \\
\hline \multicolumn{6}{|l|}{ BMI $\left(\mathrm{kg} / \mathrm{m}^{2}\right)$} \\
\hline Mean & 14.9 & & $15 \cdot 1$ & & 0.61 \\
\hline SD & 2.5 & & $2 \cdot 2$ & & \\
\hline Normal & 68 & 48.9 & 71 & $51 \cdot 1$ & 0.97 \\
\hline Thinness (BMI for age <-2 SD) & 52 & $48 \cdot 6$ & 55 & 51.4 & \\
\hline Severe thinness (BMl for age $<-3 \mathrm{SD}$ ) & 67 & $50 \cdot 0$ & 67 & $50 \cdot 0$ & \\
\hline \multicolumn{6}{|l|}{ Height for age } \\
\hline Normal & 151 & $49 \cdot 0$ & 157 & $51 \cdot 0$ & 0.97 \\
\hline Stunted (height for age <-2 SD) & 30 & $50 \cdot 9$ & 29 & $49 \cdot 1$ & \\
\hline Severe stunting (height for age $<-3 \mathrm{SD}$ ) & 7 & $50 \cdot 0$ & 7 & $50 \cdot 0$ & \\
\hline \multicolumn{6}{|l|}{ Religion } \\
\hline Hindu & 182 & $48 \cdot 3$ & 195 & $51 \cdot 7$ & 0.06 \\
\hline Muslim/Christian/Sikh/Others & 14 & $70 \cdot 0$ & 6 & $30 \cdot 0$ & \\
\hline \multicolumn{6}{|l|}{ Caste } \\
\hline Scheduled caste and tribes (SC/ST) & 87 & $43 \cdot 3$ & 114 & 57.9 & 0.003 \\
\hline Other backward classes & 21 & $77 \cdot 8$ & 6 & $22 \cdot 2$ & \\
\hline Others & 70 & $47 \cdot 6$ & 77 & $52 \cdot 4$ & \\
\hline Family type & & & & & \\
\hline Nuclear family & 123 & $45 \cdot 7$ & 146 & $54 \cdot 3$ & 0.029 \\
\hline Joint family & 73 & $57 \cdot 5$ & 54 & $42 \cdot 5$ & \\
\hline Per capita income (Rs.) & & & & & \\
\hline $\mathrm{P}_{50}$ & 1225 & & 1400 & & 0.40 \\
\hline $\mathrm{P}_{25}-\mathrm{P}_{75}$ & & & & & \\
\hline Wealth index & & & & & \\
\hline Poorest & 40 & $58 \cdot 8$ & 28 & $41 \cdot 2$ & 0.23 \\
\hline Poorer & 35 & $48 \cdot 0$ & 38 & $52 \cdot 0$ & \\
\hline Middle & 34 & $42 \cdot 0$ & 47 & $58 \cdot 0$ & \\
\hline Richer & 40 & $46 \cdot 0$ & 47 & 54.0 & \\
\hline Richest & 49 & 54.4 & 41 & $45 \cdot 6$ & \\
\hline Type of house & & & & & \\
\hline Kutcha & 7 & $58 \cdot 3$ & 5 & 41.7 & 0.49 \\
\hline Semi-pucca & 31 & 55.4 & 25 & $44 \cdot 6$ & \\
\hline Pucca & 158 & $48 \cdot 0$ & 171 & $52 \cdot 0$ & \\
\hline Name of water source & & & & & \\
\hline Community RO/filter & 11 & $47 \cdot 8$ & 12 & $52 \cdot 2$ & $<0.001$ \\
\hline Tubewell & 12 & $22 \cdot 6$ & 41 & 77.4 & \\
\hline Piped water & 78 & 54.5 & 65 & 45.4 & \\
\hline Handpump & 95 & 53.4 & 83 & $46 \cdot 6$ & \\
\hline Frequency of washing hands before consu & & & & & \\
\hline Always & 169 & $49 \cdot 0$ & 176 & $51 \cdot 0$ & 0.69 \\
\hline Sometimes & 27 & 51.9 & 25 & $48 \cdot 1$ & \\
\hline Agent used for washing hands before cons & & & & & \\
\hline Soap & 44 & $46 \cdot 3$ & 51 & 53.7 & 0.50 \\
\hline Only water & 152 & $50 \cdot 3$ & 150 & $49 \cdot 7$ & \\
\hline Type of toilet facility at home & & & & & \\
\hline Flush or pour flush toilet & 170 & 48.4 & 181 & 51.6 & 0.30 \\
\hline Pit latrine/use open space or field & 26 & $56 \cdot 5$ & 20 & 43.5 & \\
\hline Type of diet $\ddagger$ & & & & & \\
\hline Vegetarian & 157 & $49 \cdot 4$ & 161 & $50 \cdot 6$ & 0.73 \\
\hline Non-vegetarian & 15 & $55 \cdot 6$ & 12 & 44.4 & \\
\hline Eggitarian & 24 & $46 \cdot 1$ & 28 & 53.9 & \\
\hline Consumption of deworming tablets (past 1 & & & & & \\
\hline No & 31 & $43 \cdot 1$ & 41 & $56 \cdot 9$ & 0.23 \\
\hline Yes & 166 & $50 \cdot 9$ & 160 & $49 \cdot 1$ & \\
\hline
\end{tabular}


Table 2 Continued

\begin{tabular}{|c|c|c|c|c|c|}
\hline \multirow[b]{2}{*}{ Parameters } & \multicolumn{2}{|c|}{$\begin{array}{c}\text { Non-anaemia group } \\
(n 198)\end{array}$} & \multicolumn{2}{|c|}{$\begin{array}{l}\text { Anaemia group } \\
(n 202)\end{array}$} & \multirow[b]{2}{*}{$P$ value } \\
\hline & $n$ & $\%$ & $n$ & $\%$ & \\
\hline \multicolumn{6}{|c|}{ Consumed IFA tablets at school (past $30 \mathrm{~d}$ ) } \\
\hline Yes & 172 & $51 \cdot 8$ & 160 & $48 \cdot 2$ & 0.020 \\
\hline No & 23 & 35.9 & 41 & $64 \cdot 1$ & \\
\hline \multicolumn{6}{|c|}{ Status of menstruation } \\
\hline Menstruating & 123 & $43 \cdot 8$ & 158 & $56 \cdot 2$ & $<0.001$ \\
\hline Not menstruating & 75 & 63.0 & 44 & $37 \cdot 0$ & \\
\hline
\end{tabular}

*Values are expressed as Mean $\pm \mathrm{SD}$

†Values are expressed as $P_{50}\left(P_{25}-P_{75}\right)$.

$\ddagger$ Vegetarian diet includes cereals, pulses, fruits and milk and milk products.

Eggitarian diet includes vegetarian diet + eggs.

Non-vegetarian diet includes eggitarian diet + and meat products.

Table 3 Comparison of anaemia-related biomarkers in the two groups

\begin{tabular}{|c|c|c|c|c|c|c|c|c|c|c|}
\hline \multirow[b]{2}{*}{ Parameters } & \multicolumn{3}{|c|}{ Non-anaemia group } & \multicolumn{3}{|c|}{ Anaemia group } & \multirow[b]{2}{*}{$P$ value } & \multirow{2}{*}{$\begin{array}{l}\beta \text { coeffi- } \\
\text { cient } \S\end{array}$} & \multirow[b]{2}{*}{$95 \% \mathrm{Cl}$} & \multirow{2}{*}{$\begin{array}{l}P \text { value } \\
2 \S\end{array}$} \\
\hline & $n$ & Mean & $95 \% \mathrm{Cl}$ & $n$ & Mean & $95 \% \mathrm{Cl}$ & & & & \\
\hline Ferritin (log) $(\mathrm{ng} / \mathrm{ml})^{\star}$ & 188 & $3 \cdot 3$ & $3 \cdot 2,3 \cdot 4$ & 200 & $2 \cdot 8$ & $2 \cdot 7,2 \cdot 9$ & $<0.001$ & -0.38 & $-0.55,-0.21$ & $<0.001$ \\
\hline $\begin{array}{l}\text { Soluble transferrin receptor }(\mathrm{mg} / \mathrm{l}) \\
\mathrm{P}_{50}\left(\mathrm{P}_{25}-\mathrm{P}_{75}\right)\end{array}$ & 168 & $\begin{array}{l}1.5 \\
1.4\end{array}$ & $\begin{array}{l}1.4,1.6 \\
1.1,1.9\end{array}$ & 147 & $\begin{array}{l}1.4 \\
1.6\end{array}$ & $\begin{array}{l}1 \cdot 2,1 \cdot 6 \\
0 \cdot 2,2 \cdot 0\end{array}$ & $0.70 \ddagger$ & -0.04 & $-0.29,0.20$ & 0.71 \\
\hline $\begin{array}{l}\text { Soluble transferrin receptor/log } \\
\text { ferritin }(\mathrm{mg} / \mu \mathrm{g}) \dagger\end{array}$ & 159 & 0.5 & $0.4,0.5$ & 145 & 0.5 & $0.4,0.6$ & $0.18 \ddagger$ & 0.06 & $-0.04,0.16$ & 0.25 \\
\hline$P_{50}\left(P_{25}-P_{75}\right)$ & & 0.4 & $0.3,0.6$ & & 0.5 & $0.1,0.7$ & & & & \\
\hline $\begin{array}{l}\text { Hepcidin (ng/ml) } \\
\mathrm{P}_{50}\left(\mathrm{P}_{25}-\mathrm{P}_{75}\right)\end{array}$ & 182 & $\begin{array}{l}170 \cdot 4 \\
114 \cdot 8\end{array}$ & $\begin{array}{r}149 \cdot 3,191 \cdot 6 \\
89 \cdot 3,182 \cdot 5\end{array}$ & 180 & $\begin{array}{l}203 \cdot 5 \\
123 \cdot 0\end{array}$ & $\begin{array}{r}182 \cdot 4,224 \cdot 5 \\
86 \cdot 8,312 \cdot 9\end{array}$ & $0 \cdot 13 \ddagger$ & $31 \cdot 16$ & $0.46,61 \cdot 86$ & 0.047 \\
\hline $\begin{array}{l}\text { Serum folate }(\mathrm{ng} / \mathrm{ml}) \\
P_{50}\left(P_{25}-P_{75}\right)\end{array}$ & 182 & $\begin{array}{r}9 \cdot 7 \\
12 \cdot 0\end{array}$ & $\begin{array}{l}9 \cdot 2,10 \cdot 2 \\
7 \cdot 4,12 \cdot 0\end{array}$ & 189 & $\begin{array}{l}7 \cdot 7 \\
8 \cdot 8\end{array}$ & $\begin{array}{l}7 \cdot 1,8 \cdot 3 \\
3 \cdot 7,12 \cdot 0\end{array}$ & $<0.001 \ddagger$ & -1.95 & $-2 \cdot 76,-1 \cdot 14$ & $<0.001$ \\
\hline $\begin{array}{l}\text { Vitamin } B_{12}(\mathrm{pg} / \mathrm{ml}) \\
\mathrm{P}_{50}\left(\mathrm{P}_{25}-\mathrm{P}_{75}\right)\end{array}$ & 188 & $\begin{array}{l}245 \cdot 4 \\
234 \cdot 0\end{array}$ & $\begin{array}{l}234 \cdot 7,256 \cdot 1 \\
198 \cdot 0,282 \cdot 5\end{array}$ & 200 & $\begin{array}{l}250 \cdot 7 \\
238 \cdot 0\end{array}$ & $\begin{array}{l}240 \cdot 6,260 \cdot 7 \\
202 \cdot 5,280 \cdot 5\end{array}$ & 0.48 & 1.57 & $-14 \cdot 12,17 \cdot 26$ & 0.84 \\
\hline
\end{tabular}

*Ferritin values were log transformed.

†Soluble transferrin receptor/log ferritin ratio estimates the body Fe across normal and depleted Fe stores.

$¥$ Mann-Whitney test performed.

$\S P$ value 2: Adjusted for age, CRP, caste, source of water, reported consumption of IFA and status of menstruation.

On adjusted analysis, anaemic participants had significantly lower ferritin $(\beta,-0.38 ; P<0.001)$, folate $(\beta,-1.95 ; P<0.001)$ and higher hepcidin levels $(\beta, 31 \cdot 16$; $P=0.047)$. However, the serum levels of sTfR, sTfR log ferritin and vitamin $\mathrm{B}_{12}$ were comparable in both the groups (Table 3).

\section{Characterisation of anaemia}

Anaemic girls had significantly higher proportion of Fe deficiency as compared with non-anaemic girls (IDA: $29.6 \% v$. Fe deficiency with no anaemia $11.0 \%, P<0.001$ ) (Table 4). High prevalence of folate or vitamin $\mathrm{B}_{12}$ deficiency was observed in both the anaemic (28.1\%) and non-anaemic groups $(29.5 \%)$. However, isolated folate deficiency was higher in anaemic subjects $(25.1 \% v .8 .2 \% ; P<0.001)$. Mixed deficiency characterised by deficiency of Fe with folate or vitamin $\mathrm{B}_{12}$ was higher in anaemic participants $(15.8 \% v .6 .4 \% ; P=0.004)$. Acute inflammation was found in $9.7 \%$ anaemic and $14.4 \%$ non-anaemic girls. Anaemia of other causes was observed in $16.8 \%$ anaemic participants.
Anaemic participants had significantly higher odds of having Fe deficiency (AOR: 2.49, $95 \%$ CI $(1.34,4.61)$, $P=0.004$ ), isolated folate deficiency (AOR: $3.95,95 \% \mathrm{CI}$ $(2 \cdot 03,7 \cdot 71), P<0 \cdot 001)$ and mixed deficiency (AOR: $2 \cdot 40$, $95 \%$ CI (1.15, 4.99), $P=0.019)$ (Table 4).

\section{Discussion}

The study population had comparable stunting rates but higher prevalence of thinness, severe thinness than the national average for adolescents in the age group of 10-19 years ${ }^{(1)}$. However, in congruence with an earlier systematic review ${ }^{(22)}$, anaemia had no association with BMI and stunting amongst adolescent girls. Adolescent girls above 15 years had higher proportion of anaemia possibly due to the high Fe demands of the body due to mensuration and for supporting accelerated growth ${ }^{(23)}$. In the present study, half of the adolescent girls belonged to SC/ST and anaemia was found to be highest amongst them. In 
Table 4 Characterisation of anaemia amongst adolescent girls aged 12-19 years

\begin{tabular}{|c|c|c|c|c|c|c|c|c|c|c|}
\hline \multirow[b]{2}{*}{ Parameters } & \multicolumn{3}{|c|}{ Non-anaemia group } & \multicolumn{3}{|c|}{ Anaemia group } & \multirow[b]{2}{*}{$\begin{array}{c}P \\
\text { value }\end{array}$} & \multirow[b]{2}{*}{$\begin{array}{l}\text { Odds } \\
\text { ratio* }\end{array}$} & \multirow[b]{2}{*}{$95 \% \mathrm{Cl}$} & \multirow[b]{2}{*}{$\begin{array}{c}P \\
\text { value } 2^{*}\end{array}$} \\
\hline & $\begin{array}{c}\text { Total } \\
n\end{array}$ & $\begin{array}{l}\text { Deficient } \\
\%\end{array}$ & $95 \% \mathrm{Cl}$ & $\begin{array}{c}\text { Total } \\
n\end{array}$ & $\begin{array}{l}\text { Deficient } \\
\%\end{array}$ & $95 \% \mathrm{Cl}$ & & & & \\
\hline Fe deficiency & 173 & $11 \cdot 0$ & $7 \cdot 1,16 \cdot 6$ & 196 & $29 \cdot 6$ & $23 \cdot 6,36 \cdot 4$ & $<0.001$ & 2.49 & $1 \cdot 34,4.62$ & 0.004 \\
\hline Folate or vitamin $B_{12}$ deficiency & 173 & 29.5 & $23 \cdot 1,36 \cdot 7$ & 196 & $28 \cdot 1$ & $22 \cdot 2,34 \cdot 8$ & 0.76 & - & & - \\
\hline - Isolated folate $(<4 \mathrm{ng} / \mathrm{ml})$ & 182 & $8 \cdot 2$ & $5 \cdot 0,13 \cdot 2$ & 203 & $25 \cdot 1$ & $19 \cdot 6,31 \cdot 5$ & $<0.001$ & 3.95 & $2 \cdot 03,7.71$ & $<0.001$ \\
\hline $\begin{array}{l}\text { - Isolated vitamin } B_{12} \\
(<203 \mathrm{pg} / \mathrm{ml})\end{array}$ & 188 & $28 \cdot 7$ & $22 \cdot 7,35 \cdot 6$ & 213 & $26 \cdot 8$ & $21 \cdot 2,33 \cdot 1$ & 0.66 & - & & - \\
\hline Mixed deficiency & 173 & $6 \cdot 4$ & $3.5,11 \cdot 1$ & 196 & $15 \cdot 8$ & $11 \cdot 3,21 \cdot 7$ & 0.004 & $2 \cdot 40$ & $1.15,4.99$ & 0.019 \\
\hline Inflammation & 173 & 14.4 & $9 \cdot 9,20 \cdot 6$ & 196 & $9 \cdot 7$ & $6 \cdot 2,14 \cdot 7$ & $0 \cdot 16$ & - & & - \\
\hline Other causes & - & - & & 196 & $16 \cdot 8$ & $12 \cdot 2,22 \cdot 8$ & & - & & - \\
\hline
\end{tabular}

${ }^{*} P$ value 2: Adjusted for age, caste, source of water, CRP, reported consumption of IFA and status of menstruation.

India, a bulk of this SC/ST population fall in the lowest two wealth brackets, which breeds subclinical infection and relatively poorer quality of diets.

Our study characterises anaemia amongst rural adolescent girls in India. Fe deficiency (29.6\%) was the leading contributor of anaemia followed by folate and vitamin $\mathrm{B}_{12}$ deficiency (28.1\%). Mixed deficiency of Fe, folate and vitamin $B_{12}$ was found in $15.9 \%$ of the anaemic girls. Deficiencies of Fe, folic acid, vitamin $\mathrm{B}_{12}$ and their mixed deficiency together contributed to $73.5 \%$ of the anaemia amongst adolescent girls. The recent Comprehensive National Nutrition Survey conducted in India amongst 1912 anaemic adolescent girls reported similar proportion of $\mathrm{Fe}$ deficiency $(26.8 \%)$ and folate or vitamin $\mathrm{B}_{12}$ deficiency $(22 \cdot 2 \%)^{(5)}$. Findings of the present study are consistent with the global evidence that Fe deficiency contributes to less than half of the nutritional anaemia amongst Indian adolescent girls ${ }^{(3,24,25)}$. The Biomarkers Reflecting Inflammation and Nutritional Determinants of Anemia project consisting of nationally representative data from ten surveys of women of reproductive age (15-49 years), reported that in low- and middle-income countries where inflammation levels were high, Fe deficiency (7-35\%) played a much smaller role in the etiology of anaemia ${ }^{(24)}$. Another systematic analysis of National surveys found that in countries where anaemia prevalence was $>40 \%$, especially in rural populations, Fe deficiency contributed to only $16 \%$ anaemia among women of reproductive age ${ }^{(4)}$.

In the present study, more than $10 \%$ of the participants were found to have Fe deficiency with no anaemia. Fe deficiency may be present despite a normal haemoglobin and full blood count as Fe deficiency anaemia is a late manifestation of Fe deficiency ${ }^{(26-28)}$. Fe deficiency with no anaemia has been associated with many symptoms such as menorrhagia $^{(29)}$, dizziness ${ }^{(29)}$, dyspnoea ${ }^{(29)}$, fatigue ${ }^{(30)}$, reduced quality of life ${ }^{(31)}$ and mood disturbances ${ }^{(32)}$.

The combined deficiency of folate and vitamin $\mathrm{B}_{12}$ deficiency was presented in more than one-fifth of the anaemic and non-anaemic girls. Anemic girls had significantly lower isolated folate levels and folate deficient girls had 4.17 times higher odds of anaemia. Contrary to other studies $^{(33,34)}$, a cross-sectional research conducted amongst Indian tribal adolescent boys and girls aged 10 to 17 years reported no association of anaemia with folate deficiency. They also reported that girls were 3.8 times more likely than boys to be deficient in folate ${ }^{(35)}$. Earlier studies conducted in Kuwait also reported no significant association of folate with anaemia and $<10 \%$ prevalence of anaemia in the adolescents with low folate status ${ }^{(36,37)}$.

Folate is known to work closely with vitamin $\mathrm{B}_{12}$ during erythropoiesis. Deficiency of folate slows formation and maturation of RBC. Low concentration of vitamin $\mathrm{B}_{12}$ in turn contributes to the reduced formation of metabolically active folate, reduced folate retention in developing RBC and indirect induction of intracellular folate deficiency. Thus, coexisting vitamin $\mathrm{B}_{12}$ deficiency has been suggested to negatively affect and further precipitate folate deficiency ${ }^{(38)}$.

The role of vitamin $\mathrm{B}_{12}$ in the aetiology of anaemia has been inconsistent ${ }^{(3,39,40)}$. In the present study, serum vitamin $\mathrm{B}_{12}$ was similar between both anaemic and nonanaemic groups. A study conducted to assess the haematological status of Indian adolescent girls residing in an urban slum in West Delhi reported that serum levels of serum ferritin, folic acid and vitamin $\mathrm{B}_{12}$ decreased and the deficiency increased linearly with the increasing severity of anaemia ${ }^{(34)}$. Similar trends in serum ferritin, folic acid and vitamin $B_{12}$ were reported by another cross-sectional hospital-based study among 200 Indian adolescents (10-18 years) with anaemia ${ }^{(33)}$. However, earlier RCT assessing the effect of supplementation of vitamin $\mathrm{B}_{12}$ have also shown no beneficial effect on haemoglobin levels ${ }^{(41,42)}$. Studies have suggested that anaemia due to vitamin $B_{12}$ deficiency does not usually appear until an individual has a relatively severe state of depletion ${ }^{(43,44)}$. Estimation of one biomarker of circulating vitamin $\mathrm{B}_{12}$ (serum vitamin $\mathrm{B}_{12}$ or holotranscobalamin) and one functional biomarker (MMA or tHcy) may specify the true vitamin $\mathrm{B}_{12}$ status ${ }^{(45)}$. Hence, further studies may utilise an additional functional biomarker to document its association with anaemia. 
In our study, high prevalence of inflammation was observed amongst both anaemic (9.7\%) and non-anaemic (14.4\%) adolescent girls. Anaemia of inflammation deregulates the synthesis of hepcidin, master regulator of $\mathrm{Fe}$ homoeostasis. This leads to the degradation of ferroportin-1 exporter and sequestration of $\mathrm{Fe}$ and therefore inhibiting the entry of $\mathrm{Fe}$ into plasma and systemic circulation causing a pseudo deficiency situation ${ }^{(46)}$ and reduced Fe bioavailability ${ }^{(47)}$. Urinary and serum hepcidin has been documented to increase to up to 100-fold during infections and inflammation. Hepcidin levels may therefore distinguish individuals with Fe deficiency anaemia $v$. anaemia of inflammation ${ }^{(47)}$.

We found that the mean hepcidin levels were higher amongst anaemic adolescent girls. Hepcidin was documented to be significantly associated with haemoglobin, ferritin and sTfR amongst Sri Lankan adolescents ${ }^{(48)}$. A recent study conducted to assess the relative maturity of serum hepcidin in the setting of IDA reported differing results as hepcidin was significantly lower in children (6 months - 18.2 years) with IDA than in the control participants ${ }^{(49)}$. The authors concluded that inhibited maturation and synthesis of hepcidin in children and unadjusted values of hepcidin for age may have resulted in its low concentration in $\operatorname{IDA}^{(49)}$.

A possible source of inflammation may have been the water from unclean water sources as more than $40 \%$ of the rural adolescent girls consumed untreated water from the handpumps. Inflammation may have been further exacerbated by poor hand washing practices as majority (75.5\%) of the girls washed their hands only with water before consuming food. Chronic intestinal inflammation can lead to atrophy of the intestinal villi and impaired absorption of haematopoietic nutrients from the diet, without obvious diarrhoea ${ }^{(50,51)}$. Evidence suggests that children exposed to long-term poor quality of water, sanitation and hygiene conditions and open defecation have lower haemoglobin levels due to increased risk of intestinal infection and chronic gut inflammation ${ }^{(52,53)}$.

Our study was conducted in rural areas, and the markers for nutritional anaemia such as Fe deficiency including the utilisation marker hepcidin, folate, vitamin $\mathrm{B}_{12}$ deficiency and inflammation were evaluated simultaneously in both anaemic and non-anaemic adolescent girls. However, the following limitations merit consideration. We utilised filter paper for estimation of haemoglobin due to logistic reasons. This could have underestimated haemoglobin and overestimated anaemia ${ }^{(54)}$. Further, budgetary constraints precluded evaluation of other causes of anaemia including haemoglobinopathies, vitamin A status and hookworm infestation and chronic inflammation using $\alpha$-1-acid glycoprotein. Adolescent girls who were not going to school could not be included due to feasibility issues. Another limitation of the study is that we did not collect information on the history of diarrhaeal episodes.
Prevention and control of anaemia in adolescent girls, the future mothers, needs to be addressed on a priority. The current strategy of IFA supplementation alone will not suffice for achieving the desired reduction in the prevalence of anaemia as unknown causes (16.8\%), and anaemia of inflammation ( $9.7 \%)$ contributes to a substantial proportion of anaemia.

In addition, high prevalence of $\mathrm{Fe}$, folic acid, vitamin $\mathrm{B}_{12}$ deficiencies and inflammation among non-anaemic girls places them at an increased risk of developing anaemia. Currently, no government strategy exists for testing and addressing these deficiencies in non-anaemic children, even amongst those presenting with symptoms.

The findings of our study suggest development and implementation of strategies that converge anaemiaspecific programme with all other nutrition-specific components like improving water, sanitation and hygiene practices. Such strategies will comprehensively tackle anaemia by reaching all anaemic and non-anaemic adolescent girls. Further studies are needed to characterise the additional important determinants of anaemia in adolescents.

\section{Highlights of the study}

1. Fe deficiency was the leading contributor of anaemia amongst rural adolescent girls followed by folate deficiency. The deficiency of these micronutrients along with their mixed deficiency contributes to $73.5 \%$ of the anaemia.

2. Anaemia of inflammation (9.7\%) contributes to a substantial proportion of anaemia.

3. High prevalence of $\mathrm{Fe}$, folic acid, vitamin $\mathrm{B}_{12}$ deficiencies and inflammation also exists among non-anaemic groups.

4. Unknown causes of anaemia amongst one-sixth of the anaemic adolescent girls warrant the need for further studies to understand the aetiology of anaemia.

\section{Acknowledgements}

Acknowledgements: We acknowledge Prof. Shashi Kant, Professor and Head, Community Medicine, All India Institute of Medical Sciences, New Delhi, for his inputs in data collection. Financial support: The present study was nested within a Department of Biotechnology, Ministry of Science and Technology, Government of India (vide letter no. BT/PR15606/PFN/20/1188/2015) funded community-based cluster-randomised. This particular research did not receive any specific grant from funding agencies in the public, commercial or not-for-profit sectors. Conflict of interest: The authors declare no conflict of interest. Authorship: A.G.: Conceptualisation, data 
curation, formal analysis, investigation, methodology, project administration, supervision; validation, visualisation, roles/writing - original draft, writing - review and editing. H.P.S.S.: Conceptualisation, investigation, methodology, project administration, supervision, validation, visualisation, writing - review and editing. U.K.: Conceptualisation, investigation, methodology, project administration, supervision, validation, visualisation, funding acquisition, resources, software. S.P.: Data curation, investigation, validation, visualisation. R.M.P.: Conceptualisation, data curation, formal analysis. H.C.S.: Conceptualisation, data curation, formal analysis. L.K.S.: Conceptualisation, data curation, investigation, validation and visualisation. P.R.L.: Conceptualisation, investigation, methodology, project administration, supervision, validation, visualisation, writing - review and editing. Ethics of buman subject participation: All procedures performed in studies involving human participants were in accordance with the ethical standards of the institutional and/or national research committee and with the 1964 Helsinki Declaration and its later amendments or comparable ethical standards.

\section{References}

1. Ministry of Health and Family Welfare (MoHFW), Government of India, UNICEF et al. (2019) Comprehensive National Nutrition Survey (CNNS) National Report. New Delhi: MoHFW.

2. UNICEF (2002) Prevention and Control of Nutritional Anaemia - A South Asia Priority. https://hetv.org/pdf/ anaemia-pc.pdf (accessed September 2021).

3. World Health Organization (2015) The Global Prevalence of Anaemia in 2011. Geneva: World Health Organization.

4. Petry N, Olofin I, Hurrell RF et al. (2016) The proportion of anemia associated with iron deficiency in low, medium, and high human development index countries: a systematic analysis of national surveys. Nutrients $\mathbf{8}, 693$.

5. Sarna A, Porwal A, Ramesh S et al. (2020) Characterisation of the types of anaemia prevalent among children and adolescents aged 1-19 years in India: a population-based study. Lancet Child Adolesc Health 4, 515-525.

6. Lahiri A, Singh KD, Ramaswamy G et al. (2020) Iron deficiency is the strongest predictor of anemia in indian adolescents aged 10-19 years: evidence from the comprehensive national nutrition survey. Curr Dev Nutr 4, 1819.

7. Ministry of Health and Family Welfare (2018) Anemia Mukt Bharat: Intensified National Iron Plus Initiative. https:// anemiamuktbharat.info/resources/ (accessed September 2021).

8. International Institute of Population Sciences, India. National Family Health Survey. http://rchiips.org/nfhs/ (accessed September 2021).

9. Ministry of Home Affairs \& Government of India (2018) Sample Registration System Statistical Report 2018. https:// censusindia.gov.in/vital_statistics/SRS_Reports_2018.html (accessed January 2021).

10. Directorate of Census Operations (2011) District Census Handbook Faridabad. https://censusindia.gov.in/2011 census/dchb/0620_PART_B_DCHB_FARIDABAD.pdf (accessed January 2021).
11. International Institute for Population Sciences \& Macro International (2017) National Family Health Survey (NFHS-4), 2015-2016: India. Mumbai: IIPS.

12. Annual Status of Education Report (2019) ASER 2018-Rural. https://img.asercentre.org/docs/ASER2018/ReleaseMaterial/ aserreport2018.pdf (accessed December 2021).

13. Cook JD \& International Nutritional Anemia Consultative Group (1985) Measurement of Iron Status: A Report of the International Nutritional Anemia Consultative Group (INACG). https://www.worldcat.org/title/measurements-ofiron-status-a-report-of-the-international-nutritional-anemiaconsultative-group-inacg/oclc/19401849 (accessed June 2020).

14. Garcia-Casal MN, Peña-Rosas JP, Urrechaga E et al. (2018) Performance and comparability of laboratory methods for measuring ferritin concentrations in human serum or plasma: a systematic review and meta-analysis. PLoS One 13, $\mathrm{e} 0196576$.

15. Uotila M, Ruoslahti E \& Engvall E (1981) Two-site sandwich enzyme immunoassay with monoclonal antibodies to human alpha-fetoprotein. J Immunol Methods 42, 11-15.

16. World Health Organization (2011) Haemoglobin Concentrations for the Diagnosis of Anaemia and Assessment of Severity. https://apps.who.int/iris/bitstream/ handle/10665/85839/WHO_NMH_NHD_MNM_11.1_eng.pdf? sequence $=228$ isAllowed $=\mathrm{y}$ (accessed June 2020).

17. World Health Organization (2020) WHO Guideline on Use of Ferritin Concentrations to Assess Iron Status in Individuals and Populations. Geneva: World Health Organization.

18. de Benoist B (2008) Conclusions of a WHO technical consultation on folate and vitamin B12 deficiencies. Food Nutr Bull 29. S238-S244.

19. World Health Organization (2014) C-Reactive Protein Concentrations as a Marker of Inflammation or Infection for Interpreting Biomarkers of Micronutrient Status. Geneva: World Health Organization.

20. Filmer D \& Pritchett L (2001) Estimating wealth effects without expenditure data - or tears: an application to educational enrollments in states of India. Demography 38, 115-132.

21. World Health Organization (2007) Growth Reference 5-19 Years. https://www.who.int/growthref/who2007_bmi_for_ age/en/ (accessed May 2020).

22. McCuskee S, Brickley EB, Wood A et al. (2014) Malaria and macronutrient deficiency as correlates of anemia in young children: a systematic review of observational studies. Ann Glob Health 80, 458-465.

23. World Health Organization (2006) Adolescent Nutrition: A Review of the Situation in Selected South-East Asian Countries. New Delhi: Regional Office of South-East Asia; available at https://apps.who.int/iris/bitstream/ handle/10665/204764/B0239.pdf?sequence=1\&isAllowed=y (accessed June 2020).

24. Wirth JP, Woodruff BA, Engle-Stone R et al. (2017) Predictors of anemia in women of reproductive age: biomarkers reflecting inflammation and nutritional determinants of anemia (BRINDA) project. Am J Clin Nutr 106, 416S-427S.

25. Stevens GA, Finucane MM, De-Regil LM et al. (2013) Global, regional, and national trends in haemoglobin concentration and prevalence of total and severe anaemia in children and pregnant and non-pregnant women for 1995-2011: a systematic analysis of population-representative data. Lancet Glob Health 1, 16-25.

26. Lopez A, Cacoub P, Macdougall IC et al. (2016) Iron deficiency anaemia. Lancet 387, 907-916.

27. Camaschella C (2015) Iron-deficiency anemia. N Engl J Med 372, 1832-1843. 
28. Soppi ET (2018) Iron deficiency without anemia - a clinical challenge. Clin Case Rep 6, 1082-1086.

29. Abuaisha M, Itani H, El Masri R et al. (2020) Prevalence of iron deficiency (ID) without anemia in the general population presenting to primary care clinics: a cross-sectional study. Postgrad Med 132, 282-287.

30. Sawada T, Konomi A \& Yokoi K (2014) Iron deficiency without anemia is associated with anger and fatigue in young Japanese women. Biol Trace Elem Res 159, $22-31$.

31. Grondin M-A, Ruivard M, Perrève A et al. (2013) Prevalence of iron deficiency and health-related quality of life among female students. J Am Coll Nutr 27, 337-341.

32. Sheikh M, Hantoushzadeh S, Shariat M et al. (2015) The efficacy of early iron supplementation on postpartum depression, a randomized double-blind placebo-controlled trial. Eur J Nutr 56, 901-908.

33. Thomas D, Chandra J, Sharma S et al. (2015) Determinants of nutritional anemia in adolescents. Indian Pediatr 52, 867-869.

34. Bansal PG, Toteja GS, Bhatia N et al. (2015) Deficiencies of serum ferritin and vitamin $B_{12}$, but not folate, are common in adolescent girls residing in a slum in Delhi. Int J Vitam Nutr Res 85, 14-22.

35. Jani R, Salian N, Udipi S et al. (2015) Folate status and intake of tribal Indian adolescents aged 10 to 17 years. Food Nutr Bull 36, 14-23.

36. Shaban L, Al-Taiar A, Rahman A et al. (2020) Anemia and its associated factors among adolescents in Kuwait. Sci Rep 10, $1-9$.

37. Al ZS, Alomirah H, Al HS et al. (2015) Prevalence and determinants of anemia and iron deficiency in Kuwait. Int J Environ Res Public Health 12, 9036-9045.

38. Rosenthal J, Largaespada N, Bailey LB et al. (2017) Folate deficiency is prevalent in women of childbearing age in Belize and is negatively affected by coexisting vitamin $B_{12}$ deficiency: belize national micronutrient survey 2011. J Nutr 147, 1183-1193.

39. Kumar T, Taneja S, Yajnik CS et al. (2014) Prevalence and predictors of anemia in a population of North Indian children. Nutrition 30, 531-537.

40. Tripathi R, Gupta S, Rai S et al. (2013) Short-term, highdose iron supplementation to healthy pregnant women increases oxidative stress markers: implications for use of phytonutrients. Ann Phytomedicine 2, 71-78.
41. Kumar T, Taneja S, Sachdev HPS et al. (2017) Supplementation of vitamin $\mathrm{B}_{12}$ or folic acid on hemoglobin concentration in children 6-36 months of age: a randomized placebo controlled trial. Clin Nutr 36, 986-991.

42. Bansal PG, Toteja GS, Bhatia N et al. (2016) Impact of weekly iron folic acid supplementation with and without vitamin $B_{12}$ on anaemic adolescent girls: a randomised clinical trial. EurJ Clin Nutr 70, 730-737.

43. World Health Organization (2015) Serum and Red Blood Cell Folate Concentrations for Assessing Folate Status in Populations. http://apps.who.int/iris/bitstream/ handle/10665/75584/WHO_NMH_NHD_EPG_12.1_eng.pdf? sequence $=1$ (accessed June 2020).

44. Allen LH (2014) Causes of vitamin $\mathrm{B}_{12}$ and folate deficiency. Food Nutr Bull 29, 20-34.

45. Yetley EA, Pfeiffer CM, Phinney KW et al. (2011) Biomarkers of vitamin $\mathrm{B}_{12}$ status in NHANES: a roundtable summary. $\mathrm{Am}$ J Clin Nutr 94, 313S-321S.

46. Jones E, Pasricha S-R, Allen A et al. (2015) Hepcidin is suppressed by erythropoiesis in hemoglobin $\mathrm{E} \beta$-thalassemia and $\beta$-thalassemia trait. Blood 125, 873-880.

47. Pagani A, Nai A, Silvestri L et al. (2019) Hepcidin and anemia: a tight relationship. Front Physiol 10, 1294.

48. Wray K, Allen A, Evans E et al. (2017) Hepcidin detects iron deficiency in Sri Lankan adolescents with a high burden of hemoglobinopathy: a diagnostic test accuracy study. Am J Hematol 92, 196-203.

49. Chun S, Jeon JS \& Lee MJ (2019) Serum hepcidin to prohepcidin ratio in children with iron deficiency anemia. Ann Clin Lab Sci 49, 639-644.

50. Watanabe K \& Petri WA (2016) Environmental enteropathy: elusive but significant subclinical abnormalities in developing countries. EBioMedicine 10, 25-32.

51. Ngure FM, Reid BM, Humphrey JH et al. (2014) Water, sanitation, and hygiene (WASH), environmental enteropathy, nutrition, and early child development: making the links. Ann N Y Acad Sci 1308, 118-128.

52. Coffey D \& Spears D (2018) Implications of WASH benefits trials for water and sanitation. Lancet Glob Health 6, e615.

53. Coffey D (2014) Sanitation Externalities, Disease, and Children's Anemia. https://paa2014.princeton.edu/papers/ 140309 (accessed June 2020).

54. Bansal PG, Toteja GS, Bhatia N et al. (2016) Comparison of haemoglobin estimates using direct \& indirect cyanmethaemoglobin methods. Indian J Med Res 144, 566-571. 